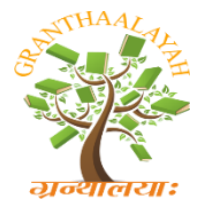

$$
\begin{gathered}
\text { INTERNATIONAL JOURNAL OF RESEARCH - } \\
\text { GRANTHAALAYAH } \\
\text { A knowledge Repository }
\end{gathered}
$$

Management

\title{
TOWARDS EFFECTIVE CUSTOMER RELATIONSHIP MANAGEMENT IN OMAN: ROLE OF BIG DATA
}

\author{
Tarek Khalil ${ }^{1}$, Mohammad Al-Refai ${ }^{2}$, Amer Nizar Fayez ${ }^{3}$, Mohammed Sharaf Qudah ${ }^{4}$ \\ ${ }^{1,2,3,4}$ IST Department, Sur University Collage, Oman
}

\begin{abstract}
We established a framework to explore the feasibility of enabling big data within the customer relationship management (CRM) strategies in Oman for creating sustainable business profit nationwide. A qualitative evaluation was made based on predictive analytics convergence and big data facilitated CRM. It was found that the big data analytics can meticulously alter the competitive industrial setting, and thereby proffered notable benefits to the business organization in terms of operation, strategies, and competitiveness. Results revealed that companies must introduce analytical tools, real-time data, and hire talented as well as skilled employees to improve the productivity in consistent with the new business model. Furthermore, depending on the customer engagement, an assemblage and analysis of enormous data volume together with analytical tools was discerned to assist companies towards efficient resource allocation and capital spending. The implications of using big data for CRM in Oman and way forward were emphasized.
\end{abstract}

Keywords: Big Data; CR; Competitive Advantage; Business Model; Analytical Tools.

Cite This Article: Tarek Khalil, Mohammad Al-Refai, Amer Nizar Fayez, and Mohammed Sharaf Qudah. (2017). "TOWARDS EFFECTIVE CUSTOMER RELATIONSHIP MANAGEMENT IN OMAN: ROLE OF BIG DATA." International Journal of Research - Granthaalayah, 5(10), 92-100. https://doi.org/10.29121/granthaalayah.v5.i10.2017.2286.

\section{Introduction}

Extremely dynamic and exigent environment of current global business persistently demands the creation of innovative strategies to achieve enhanced performance as well as enduring profits towards service and manufacturing. Comprehensive literature survey revealed that business quality alone may not suffice the economic transformation in terms of technology-driven demands of qualified customers. Thus, by introducing novel strategies such as big data analytics and capitalizing the competitive business advantage intelligently, companies can attract and retain their clients and thereby remain competitive worldwide. Sultanate Oman being a fast developing nation has intensively been implementing the new business model for sustainable business profits and development where customer relationship management (CRM) mediated by big data analytics is playing a decisive role. 
Presently, the rapid advancement in the information communication technology allowed us to gather vast volume and velocity of data from diverse business organizations. These technologies for the big data resource include cloud computing, social media, Internet of Things (IOT), and smart phones, has created a vast flow of data and. This new term so called "big data" is an emerging paradigm, where vast amount of useful and sensitive information, velocity, and varieties of files can be stored securely for further access. It is important to mention that, such big data volume is tricky to store, process, and analyze using conventional database technologies. The big data is characterized by four significant attributes such as volume, velocity, variety, and value (Gantz \& Reinsel, 2011). Volume signifies the huge amount of assorted data types produced from diverse resources. Velocity implies the speed at which such data can be transferred or communicated or browsed. Variety specifies the diverse types and forms of data that are gathered either in the structured or unstructured format. Value designates the most noteworthy trait of big data specifically the procedure of realizing the hidden patterns from outsized datasets.

Of late, research revealed that big data analytics are effective for varieties of fields including business, economics, gaming, health care, data mining, manufacturing, transportation, etc. to cite a few. In fact, implementation of big data analytics is advantageous for improving the perception of customers' needs and expectations, thereby developing a long-term relationship. The notion of big data not only signifies to the data itself, but also to the tools and practices that helps to analyze, process and manage a vast amount of multifaceted and rapidly escalating datasets. Thus, the word "big data" and "big data analytics" are invariably utilized in the literature. Business organizations or companies utilize big data analytics to achieve data driven benefits with enhanced targeted features or novel customized merchandises to satisfy valuable customers need. Certainly, customers' feedback (data) is precious in recognizing their behavioral patterns and developing marketing strategies aligned with their preferences (Kumar\& Reinartz. 2012). Auspiciously, the big data analytics assist the business organizations to appraise in real-time the value of the firm and the consumer. Consequently, the companies can take the opportunity to comprehend the customers' inclination or liking through multifaceted profiles and dynamical modifications of their marketing strategies, targets, and budgets to remain competitive (Choudhury \& Harrigan, 2014).

In the 21 st century business scenario, the success and intensification of a company is significantly decided by its relation with the customers and their overall satisfaction. Such demand has enforced the organizations to rely progressively more on the creation of competitive and exclusive merchandises. Consequently, the customers are attracted and satisfied themselves rather than substituted products or services. Thus, business organizations consider the customers satisfaction in the decision-making processes by receiving their regular feedback. In the new business model, the term CRM was coined to define a correlation between customer service and administrative effectiveness for developing improved marketing strategies. The primary goal of CRM is to provide the loyalty and profitability of the companies by adding extra value to the customers' preferences. In this regard, CRM is emerged as a tool to realize the targeted customers of a company via the information access or retrieving the responses from the audiences directly (Low \& Anshari, 2013). The past studies showed that by implementing the CRM successfully it is possible to remarkably enhance the company's revenues and also to reduce the defection rates as well as the costs. Truly, CRM is intrinsic for fulfilling the 
customer's demands although understanding the customers' requirements and satisfying their desires is not that simple (Wedel \& Kannan, 2016).

An all-inclusive literature review hinted that the studies involving the impact of big data on the CRM in the context of Oman are lacking (Al-Arafati, 2016). The role big data analytics in renovating the customer relationship into customer engagement for Omani enterprises is far from being understood. Furthermore, implementations of big data solutions for Omani companies faced some limitations. Actually, several enterprises are not able to comprehend how the analytic techniques can be applied to CRM to achieve enhanced performance. Presently, application of big data analytics to CRM for Omani companies facing great difficulties related to the expenditure of hiring skilled employees and the data intricacy. To resolve such issues, present study intends to determine the improved effects of big data analytics on the CRM in Omani companies for business strategies enhancement.

In spite of the dominance of the multinational enterprises, the national organizations in Oman are yet to develop ample strategies for CRM, modernization and intellectual capital to boost the business performance for taking competitive advantages. With the ever-increasing dissemination of foreign products in the Omani market, their strategies are being impersonated by the domestic companies for improved performance. Inspired by these ongoing debates, we explore the impact of big data analytics on the CRM in the context of Omani enterprises in enhancing the business strategies. The main purpose of this paper is to determine the role of big data in the Omani companies for developing an in-depth understanding of the customers need and optimizing their engagement for long-lasting benefits. The implementation of big data is expected to offer a profound transformation towards superior customers' management. Subsequently, such analytics may influence positively the time cycles, customer involvement in service development and operation costs lowering by restructuring business strategies and adding value to the customers (Chen et al., 2012).

By accomplishing the major objectives of this study, three contributions were made. First, a correlation is established between the convergence of predictive analytics and big data in the field of CRM. Some significant factors were identified that could support the alteration and optimization of business strategies in Oman to accurately predict the customers behavioral pattern. Second, it proffered a profound perception related to the obstacles in implementing the big data analytics towards CRM in Oman. To achieve this goal, some master students of business management stream were interviewed. Their thoughts and perceptions regarding the significance of big data analytics tools in their companies and CRM were recorded. Furthermore, for different marketing leaders and CRM practitioners from Oman were interviewed for improving the statistical sampling. Third, the value of customers' feedback in CRM processes and operations through big data analytics were unraveled.

The rest of the paper is organized as follows. Section 2 presents a detailed theoretical framework and revisits the relevant literatures related to big data assisted CRM in Oman. Section 3 describes the research design to accomplish the proposed objectives. The empirical analysis and its significant outcomes are underscored in the form of results, discussion, evaluation, and comparison. Section 5 concludes the paper together with future outlook. 


\section{Theoretical Framework}

Vast amount of literatures were carefully surveyed and critically analyzed to examine the feasibility of using big data in business organizations for sustainable benefits. It was acknowledged that various business sectors must understand the prospects of implementing big data analytics and undertake its value for making bigger impact in terms of revenue generation and long-term sustenance. Although the customers have been voluntarily producing huge amount of data on daily basis but they are unable to comprehend the value of their own data to the common public or users. Conversely, capable business organizations having analytical and logistic tools, as well as the mechanism to store, retrieve, explore, and visualize such big data can only understand its usefulness. Upon grasping the value of big data, companies or enterprises can modify their strategies and make better decisions by understanding their customers' behaviors, predicting market trends, and managing the services efficiently.

It was suggested (Atapattu \& Sedera, 2012) that the employment of big data in CRM could render a superior decision making progression and strategic innovation for analyzing the business. Currently, CRM enabled with big data analytics is positioned at innovative business realism. It was asserted that companies taking advantages of big data as an effective new resource can place them in a high altitude and appear as key player in the ever-competitive intensified global market rely on intellectual capital. Jeffrey (2014) acknowledged that big data is a precious asset for any company because it allows the organization to understand their customers' sentiment, behavioral pattern, and desires. Therefore, big data analytics could bring faster customer value and primarily utilized to develop the innovative strategies by the enterprises for taking useful decision. This in turn improves the CRM, renders competent tools and progressive views of the big data by taking superior decisions.

Choudhury \& Harrigan (2014) established a correlation among customers purchase histories, profiles, and behavior based on the data collected from social media sites which revealed their strong personal interests on social media. Furthermore, the data was interrelated with the customers' transaction histories and liking on Facebook to recognize the hidden patterns. Uncovering of such hidden patterns allowed the management to identify a great percentage of their high valued customers. Thus, to accurately judge the customers aspiration and their demands, it is prerequisite to combine the data from each structured or unstructured channel. Subsequently, these data must be analyzed to achieve an overall outlook and holistic insights of customers. Heller \& Parasnis (2011) opined that big data analyses allow the exploration of iterative data, achieve new insights, and generate queries that never occur before. Briefly, usage of big data analytics technologies allows combining the structured and unstructured data into Hadoop and analyzes them as a solitary dataset irrespective of data types. Certainly, the analytical results unfold completely the innovative patterns and deep insights that never existed before or even conceived using conventional analytical methods.

Tala \& Iyer (2014) introduced a practicable framework to surmount the existing literature gap and rendered some guidance for future studies, where CRM was categorized in five dimension including customer related acquisition, attraction, retention, development and equity growth. Predictive analytics (PA) was generally applied in customers' retention to anticipate their mixconfronts in the organizations and to develop intelligent decision for rectifying such disputes. 
Besides, PA techniques have been practiced in the customers' equity growth measurement, especially to envisage their lifetime worth. Meanwhile, inadequate attention was paid to the customers' acquisition and attraction in terms of targeted- and direct- marketing. It was argued (Anshari \& Lim, 2016) that the utilization of data analytics in the banking sector is helpful to know their customers for effective dialogue. Thus, such knowledge can be incorporated into the CRM for better administration and strategic innovation. By integrating the customer knowledge with CRM practices banking system could undertake a data driven strategy towards improved performances. In this regard, big data analytics can relate customers' engagement to different variables involving their behavioral patterns such as demographic, psychographic, and online conducts. Intensive review of literatures disclosed that despite the growing tendency of implementing predictive analytics techniques in CRM, a precise classification scheme for CRM is far from being developed. Present work indeed is a fair attempt to bridge such gap.

\section{Research Design}

The foremost aspiration of this study was to present an improved understanding on the synergism between big data exploitation and efficient CRM performance. To achieve such perspectives, we inspected the inherent inclination of enterprises to adopt big data analytic technologies and intelligently incorporate it into the CRM strategies so that hidden patterns are identifiable. Research data were collected via questionnaire surveys from multiple resources including literature, documents, observation, and face-to-face interview the master students of business management program working at different companies. All interviews were conducted on a oneto-one basis in order to capture their experiences, unbiased opinions, and concern regarding CRM in the respective company. The name individual respondent was kept anonymous for confidentiality. In short, the adopted research methodology is based on participatory observation having the some notable attributes. These features include the survey via inductive procedures rather than testing the hypotheses, sorting of data for qualitative analysis and further elucidation. Moreover, information and theoretical formalism was continuously compared, validated and distinguished during the data collection and analysis.

\section{Empirical Analysis}

In this work, the data were acquired from all the respondents for further evaluation on the impact of big data towards the improvement of CRM in Oman. In the questionnaire survey, following queries were included:

1) What role will big data play in transforming the business process?

2) How will big data affect the knowledge sharing and collaboration toward customer relationship management?

3) What business performance drives the adoption of big data technology?

4) How can big data change the existing business model?

5) How will big data build transparency and connection into the customer relationship management?

Several aspects of the big data in terms of its contribution, performance, and growth of companies CRM were emphasized. The outcomes of these interviews revealed a significant evidence for the transformation prospect of big data to create a value in the CRM. Many students 
working in the banking sector mentioned that the customer activities over smart mobile device and internet indeed have impact on the banking operation. For instance, marketing officer in a remote area can gather and convey real-time data on every possible transaction made by the customer. Actually, the customized services can empower the banking sector and control the wanting of valuable customers via the e-services. Likewise, several interviewees believed that "...big data analytics can help companies in the customer relationship management to reduce the operational costs, build transparency and good relationships into the CRM by lowering the market value..." Thus, it was affirmed that CRM personnel using big data analytics could simplify the intricacy of customer dealings, make sustained production, significant profits, and unbound growth. In brief, by using big data a company can quickly locate high quality suppliers and customers precisely. Moreover, the lacking of broad vision involving the prospective of big data and poor CRM assimilation into the companies' practices could prevent the successful cross-organizational implementation of analytical tools.

Incidentally, majority of the respondents pointed out that CRM of various business organizations may enclose manifolds of dissimilar data that inhibit the usage of big data analytics to foretell the demands, production capacities, and customer preferences. For instance, student A believed that "...the real-time analytics can be employed to scrutinize customer data for producing valuable insights into each customer's journey patterns that might help to speed up customer acquisition, prevent churn and more..." Therefore, assimilation of appropriate data can enhance the CRM members' efficiency via big data analytics usage and thereby can augment the company's profit together with improved endurance. Many respondents voiced out the acute shortage of talents and analytical skills which could lessen the potential of translating big data into analytical solutions. Teamwork and knowledge sharing using big data analytics could help to achieve improved decision making in the CRM and value creation. Some interviewees opined that "...we have a lot of engineers, economists, statisticians and computer scientists in the country, but their skills are limited to their area of specialization. We need professionals who can use big data analytics to bring competitive advantage for their companies..." This view clearly reflected the presence of poor data quality, shortage of talents and skilled employees in the organization which in turn could avert the data collection and analysis via big data analytics tools.

Some respondents also emphasized that big data analytics is disruptive technology in CRM, implying that CRM members not only require extra new tools, skills, and technologies but they must also rethink the business procedures and modify the operational modes. Furthermore, the budget constraints of enterprises in the CRM and the operational threat associated with the usage of big data analytics could severely limits the investment in these assets. Several interviewees mentioned that they are doubtful about their companies' analytical capabilities to use big data. In fact, manufacturers could confine big data prospect to create more value using real-time data, and advanced analytics tools. The greater is the assimilation across CRM, the more is the profit, growth, and sustenance. Moreover, the security concerns can delay the execution of big data solutions due to their velocity, volume, and varieties. Detail and systematic data (from the interviews of academic members) analyses displayed that incorporation of big data analytics in the CRM must be considered to potentially help the companies for managing the operational setting, lowering the customer acquisition costs, making profits, and log-lasting growth. The key factors that support the CRM transformation and major obstacles towards the execution of big data in companies are enlisted in Table 1. 
Results showed that the implementation of advanced big data analytics tools into companies could improve the CRM. It was demonstrated that by gathering and analyzing vast volumes of data companies could improve their long-term profit and decision quality. Nonetheless, some individual companies that are skeptic about data sharing could acquire valuable lesson from big data analytics and subsequently implement them in CRM for growth and prosperity. It was observed that most of the companies were relied on the traditional enterprise data warehouses (EDWs) and business intelligence (BI) software for customer analytics. Currently, most of the generated customer interactive data are in the bulk form, wherein traditional EDWs encountered limitations to handle such unstructured data. Moreover, structuring such data (for example, in database tables) is not only time consuming but also needs much resources, thus limits the potential value as a source of insight. Besides, a typical EDW cannot run sophisticated analytics such as clustering, click path analysis, and advanced data mining. Often, skilled personnel and expertise to use these cumbersome analytical tools are only few. It is reaffirmed that, big data analytics due to its notable attributes is inevitable to develop efficient CRM system and practices for sustainable growth and continuing benefits.

\section{Conclusion}

A systematic framework was introduced to examine the synergism of big data and CRM strategies in the context of Omani business organization that could create sustainable profit and enduring growth. Few significant contributions were made through this study. It clarified the value of big data analytics usage in CRM for efficient business operation and customer dealing. It was asserted that companies in the CRM must use vast amounts of business data (big data) to monitor and control the transactions, logistic operations, and inventory optimization. Present findings indicated that big data analytics is indeed useful for optimizing all operations in the entire CRM. The potential of using big data to improve the CRM strategies to achieve an efficient and greatly integrated system was discerned. The key factors that support the CRM transformation and the foremost obstacles that limit the use of big data analytics in companies were identified. It was found that acute shortage of talents and analytical skills, insufficient IT capabilities, alarming costs and lack of vision regarding the value of big data hindered the progression of CRM. It was suggested that big data implementation in the Omani enterprises is mandatory to improve the visibility, knowledge sharing, teamwork, strategic innovation, intellectual capital, inventory and logistic optimization. This in turn could help to build longterm competitive advantage for the companies and remain as leader in global economy. Furthermore, the companies that embed the big data analytics into CRM for day-to-day operations and processes could certainly enhance the profit margins. Briefly, to take the competitive advantage in the global business the Omani enterprises must introduce big data analytics into CRM strategies, performance, and practices. The statistics is the main limitation of this study due to the scarcity of respondents. It is worth to include other potential variables in the framework to inspect the impact of big data analytics in improving the strategic innovation in CRM. 
Table 1: The key factors that support the CRM transformation and major obstacles towards the execution of big data in companies.

\begin{tabular}{|l|l|l|}
\hline \multicolumn{1}{|c|}{$\begin{array}{c}\text { Transforming CRM and } \\
\text { potential of big data }\end{array}$} & \multicolumn{1}{|c|}{$\begin{array}{c}\text { Barriers for big data } \\
\text { implementation }\end{array}$} & \multicolumn{1}{c|}{ CRM performance } \\
\hline $\begin{array}{l}\text { Role of big data analytics in } \\
\text { CRptimization }\end{array}$ & $\begin{array}{l}\text { Companies may include } \\
\text { multiple channels for data } \\
\text { prevention using of big data } \\
\text { algorithms to predict and } \\
\text { analyze the demand and } \\
\text { customer preferences }\end{array}$ & $\begin{array}{l}\text { Reduction of costs to } \\
\text { improve long-term profit via } \\
\text { dynamic operations and } \\
\text { digital CRM }\end{array}$ \\
\hline $\begin{array}{l}\text { Use of big data analytics for } \\
\text { knowledge sharing and } \\
\text { collaboration }\end{array}$ & $\begin{array}{l}\text { Poor data quality, lack of } \\
\text { talent and skilled employees } \\
\text { inhibits the use of big data } \\
\text { analytics into CRM }\end{array}$ & $\begin{array}{l}\text { Better marketing strategy } \\
\text { and value creation }\end{array}$ \\
\hline $\begin{array}{l}\text { Big data analytics as } \\
\text { disruptive technology in } \\
\text { CRM }\end{array}$ & $\begin{array}{l}\text { Companies' budget } \\
\text { constraints in the CRM and } \\
\text { operational threat related to } \\
\text { big data analytics severely } \\
\text { limits the investment in these } \\
\text { assets. }\end{array}$ & $\begin{array}{l}\text { Efficient CRM processes to } \\
\text { generate competitive } \\
\text { advantage }\end{array}$ \\
\hline CRM visibility & $\begin{array}{l}\text { Security concerns can } \\
\text { prevent the implementation } \\
\text { of big data solutions due to } \\
\text { its velocity, volume, and } \\
\text { varieties }\end{array}$ & $\begin{array}{l}\text { Enhanced CRM efficiency } \\
\text { and profit as well as greater } \\
\text { integration }\end{array}$ \\
\hline
\end{tabular}

\section{Acknowledgement}

We would like to thank the management of Sur University Collage for the continuous support and encouragement to conduct this research. Also would like to thank the dean at Sur University Collage for his motivation toward doing this research.

\section{References}

[1] Al-Arafati, Ahmed. Customer Relationship Management and Five Forces Analysis in Nonprofit Organization in Oman International, Journal of Scientific and Research Publications, Volume 6, Issue 1, January 2016436 ISSN 2250-3153

[2] Anshari, M., Lim S. A. Customer relationship management with big data enabled in banking sector, Journal of Scientific Research and Development, 3 (4) 2016, Pages: 1-7

[3] Beyer, M.A., Laney, D. (2012). The Importance of "Big Data": A Definition. Gartner, G00235055.

[4] Chen, H., Chiang, R.H.L., and Storey, V.C. "Business intelligence and analytics: From big data to big Impact”. MIS Quarterly 36, 4, 2012, 1165-1188.

[5] Choudhury, MM. Harrigan, P 2014, 'CRM to social CRM: the integration of new technologies into customer relationship management' journal of strategic marketing, vol 22, no. 2, pp. 149-176. DOI: 10.1080/0965254X.2013.876069 
[6] Jeffrey Spiess," Using Big Data to Improve Customer Experience and Business Performance", Bell Labs Technical Journal, 2014.

[7] Kumar, V., Reinartz, W. (2012). Customer Relationship Management: Concept, Strategy, and Tools. Springer: New York.

[8] Heller Baird, C., Parasnis, G. (2011) from social media to social customer relationship management. Strategy \& Leadership. Vol.39. No.5. pp. 30-37.

[9] Low, K. C. P., Anshari, M. "Incorporating social customer relationship management in negotiation". International Journal of Electronic Customer Relationship Management, 7 (3/4), (2013); 239-252.

[10] Wedel, M., Kannan, P. K. (2016). Marketing analytics for data-rich environments. Journal of Marketing, 80(6), 97-121.

[11] Wang, L. (2016) the New Trend and Application of Customer Relationship Management under Big Data Background. Modern Economy, 7, 841-848. http://dx.doi.org/10.4236/me.2016.78087

[12] Atapattu, M., Sedera, D. "Ubiquitous Customer Relationship Management: Unforeseen Issues And Benefits," Pacific Asia Conference on Information Systems (PACIS), 2012

[13] Peppers, D., Rogers, M. "Managing customer relationship- a strategic framework," John Wiley \& Sons, Inc. Hoboken, NJ, USA, 2011

[14] Tala M., Iyer L. ( 2014) Predictive Analytics in CRM: Literature Review, Proceedings of the Southern Association for Information Systems Conference, Macon, GA, USA March 21st-22nd,

*Corresponding author.

E-mail address: tarek@ suc.edu.om 